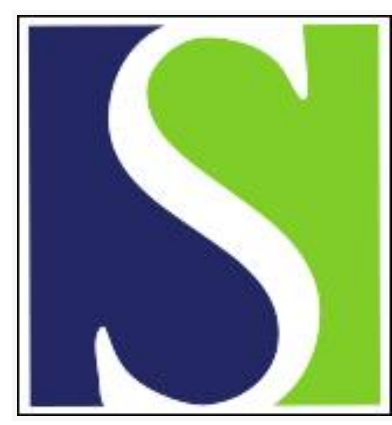

Scand J Work Environ Health 1976;2(1):13-18

https://doi.org/10.5271/sjweh.2839

Issue date: 1976

Precision and accuracy of foundry dust exposure estimates from air sampling data.

by Tossavainen A, Kokko A

Key terms: air sampling; exposure; exposure estimate; foundry dust

This article in PubMed: www.ncbi.nlm.nih.gov/pubmed/184523

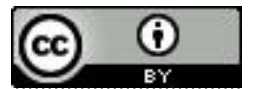




\title{
Precision and accuracy of foundry dust exposure estimates from air sampling data
}

\author{
by ANTTI TOSSAVAINEN, Lic.Sc. (Eng.), and ANTERO KOKKO, M.Sc. (Eng.) ${ }^{1}$
}

\begin{abstract}
TOSSAVAINEN, A. and KOKKO, A. Precision and accuracy of foundry dust exposure estimates from air sampling data. Scand. j. work environ. \& health 2 (1976) $13-18$. Errors in the sampling methods and in the determination of respirable size quartz in foundry dust have been evaluated and discussed. In general, the total precision of dust sampling and analysis was better than $20 \%$. The term "exposure dose" is introduced and defined. The temporal variation associated with measuring exposure dose is assessed with reference to the use of a log-normal distribution of air sampling results. The logarithmic standard deviations of dust concentrations at fixed sites
\end{abstract} and jobs are calculated.

Key words: air sampling, foundry dust, exposure.

The reliability of the conclusions drawn from air pollutant studies greatly depends on the validity of the sampling strategy and the adequacy of the statistical treatment of the concentration measurements. The development of an appropriate sampling strategy for a given situation requires the proper choice of locations, periods, and number of samples. Choice is limited by the characteristics of the particular work situation and by the sampling and analytical methods available. The strategy must take into account the inevitable errors in sample collection and analysis, as well as the sampling errors that occur when random measurements of a changing environment are made. The precision and accuracy of these components and their subsequent

1 Department of Industrial Hygiene and Toxicology, Institute of Occupational Health, Helsinki, Finland.

Reprint requests to: Mr. Antti Tossavainen, Institute of Occupational Health, Haartmaninkatu 1, FIN-00290 Helsinki 29, Finland. use compound the overall error of the estimates of contaminant exposure. In the present paper the term precision refers to the tendency of measurements to yield the same result, accuracy means the nearness of the mean of measured values to the "true" or reference value, and error equals systematic error plus random error.

Exposure data are often used for the establishment of dose-response relationships or for the determination of compliance to occupational safety standards. If a person works in a dusty environment, he is exposed to contaminated air. The amount of contamination inhaled over a given period of time can be defined as "exposure dose." Exposure dose can be calculated by multipling the mean contaminant concentration in the air by the breathing rate and by the length of exposure.

The errors inherent in gravimetric measurements of dust concentrations at workplaces are caused by (a) errors in air flow 
through the device used for sampling, (b) errors in weighing filters and dust samples, (c) errors in chemical analyses, (d) errors in locating samplers on men or at workplaces, (e) unattended operation of samplers, and (f) mistakes in handling samples. It is possible to associate quantitative estimates with the first three types of errors. Other errors in dust sampling have not, up to this time, lent themselves to quantitative evaluation.

In 1972-1975 the Finnish foundry industry was extensively surveyed and the prevalence of occupational exposure to dusts, fumes, and gases was determined. In the present paper, we have evaluated and discussed the errors associated with measuring dust exposure in this study.

\section{RESULTS}

\section{Precision of flow rate}

The personal samplers (MSA Gravimetric Sampler model G) and the lowvolume samplers (Reciprotor piston pump equipped with a dry gas meter) used in the study were calibrated against a wet test meter (Lange Gelsenkirchen). The accuracy of the wet test meter, a primary flow standard, is believed to be better than $2 \%$. In a laboratory test series with 30 personal samplers the coefficient of variation of repeated rotameter calibrations in the range of $1.5-2.0 \mathrm{l} / \mathrm{min}$ averaged $7 \%$. The same result was also achieved by Kalliokoski and Pfäffli
(5). The gas meters of the low-volume samplers had a precision of $2 \%$ (= coefficient of variation). The systematic error caused by the heating of the pump box during the operation was not corrected. This inaccuracy can be as high as $7-13 \%$ (2).

\section{Precision of weighing}

The Millipore filters (type AAWP 03700, pore size $0.8 \mu \mathrm{m}$ ), on which the dust samples were collected, varied in weight from 30 to $60 \mathrm{mg}$. The weight of dust in most samples was from 1 to $100 \mathrm{mg}$. We estimated the precision of weighing a filter by determining the weights of 50 unloaded filters before and after they had been transported and handled with the filters used for taking dust samples in foundries. The mean standard deviation of the two weights was $0.19 \mathrm{mg}$. With a 1-mg sample this would translate into a $19 \%$ coefficient of variation of weighing; with a 10-mg sample the coefficient of variation would be $1.9 \%$, etc.

The humidity of room air had a distinct effect upon the weight of a filter which had been dried in a desiccator. During the weighing the increase in weight averaged $0.015 \mathrm{mg} / \%$ relative humidity. The value reported by Jansson (3) was slightly different, i.e., $0.018 \mathrm{mg} / \%$ relative humidity. The error of the analytical balance (Sartorius model 2474, precision $0.01 \mathrm{mg}$ ) had a minor effect upon the determination of the weight of dust on a filter.

Table 1. Coefficient of variation of quartz analysis by sample type and the X-ray diffraction lines used in the determinations.

\begin{tabular}{|c|c|c|c|c|c|c|c|c|}
\hline \multirow{2}{*}{$\begin{array}{l}\text { Type of } \\
\text { sample } \\
\text { Synthetic }\end{array}$} & \multirow{2}{*}{$\begin{array}{c}\begin{array}{c}\text { Quartz } \\
\text { conc. } \\
(\% / 0)\end{array} \\
100\end{array}$} & \multirow{2}{*}{$\begin{array}{c}\begin{array}{c}\text { Number of } \\
\text { repeated } \\
\text { determin- } \\
\text { ations }\end{array} \\
5\end{array}$} & \multicolumn{6}{|c|}{ Coefficient of variation $(\%)$} \\
\hline & & & 4 & 12 & 4 & 8 & 6 & 4 \\
\hline$»$ & 90 & 5 & 3 & 12 & 2 & 7 & 8 & 7 \\
\hline$»$ & 70 & 5 & 5 & 8 & 1 & 7 & 6 & 3 \\
\hline 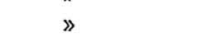 & 50 & 5 & 6 & 11 & 3 & 13 & 14 & 4 \\
\hline$»$ & 30 & 5 & 4 & 10 & 4 & 3 & 7 & 4 \\
\hline & 10 & 5 & 9 & 12 & 8 & 6 & 5 & 5 \\
\hline \multirow[t]{3}{*}{ Foundry dust } & 7 & 12 & 11 & 10 & 9 & 9 & 17 & 15 \\
\hline & \multirow{2}{*}{\multicolumn{2}{|c|}{$\begin{array}{ll}2 \Theta \mathrm{SiO}_{2} \\
2 \Theta \mathrm{CaF}_{2}\end{array}$}} & 20.85 & 20.85 & 26.67 & 26.67 & 50.15 & 50.15 \\
\hline & & & 28.30 & 47.10 & 28.30 & 47.10 & 28.30 & 47.10 \\
\hline
\end{tabular}


Precision of determining respirable size dust

The modified Andreasen sedimentation method was used for the determination of the $<5 \mu \mathrm{m}$ size fraction of the dust sample (6). We estimated the precision of the method by dividing a typical foundry dust sample with $40 \%$ respirable dust into 12 equal parts and measuring the respirable size fraction in each. In the test, the coefficient of variation was $11 \%$. Respirable dust separation is reported to have a precision of $30 \%$ at a $95 \%$ level of probability, which corresponds to a coefficient of variation of $15 \%$ (9).

\section{Precision of quartz analysis}

The concentration of quartz in the respirable dust was determined by an X-ray diffraction method with calcium fluoride as the internal standard and titanium dioxide as the matrix compound of the quartz standards (6). The quartz diffraction lines $2 \Theta=20.85^{\circ}, 26.67^{\circ}$, and $50.15^{\circ}$ and the calcium fluoride lines $2 \Theta=$ $28.30^{\circ}$ and $47.10^{\circ}$ were alternatively used in the analyses. The analytical lines actually employed were selected on the basis of interfering compounds, of which graphite $\left(2 \Theta=26.45^{\circ}\right)$ was the most common in foundry dust samples. If no interference existed, we employed the quartz line $2 \Theta=26.67^{\circ}$ and the calcium fluoride line $2 \Theta=47.10^{\circ}$ in the quantitative determination of quartz by comparing the ratio of the measured line intensities to that of calibration samples.

We estimated the precision of the cuartz analysis by measuring the quartz concentration of the 12 dust samples used in the sedimentation experiment. The mean of the determinations was $7.0 \%$ quartz with a coefficient of variation from 9 to $17 \%$ (table 1). Further experiments were performed on synthetic samples containing $10,30,50,70$, and $100 \%$ quartz with amorphous silica as a matrix compound. The results are presented in table 1.

Total precision of dust samplers and analyses

The compounding of the partial sources of imprecision in the calculation of the

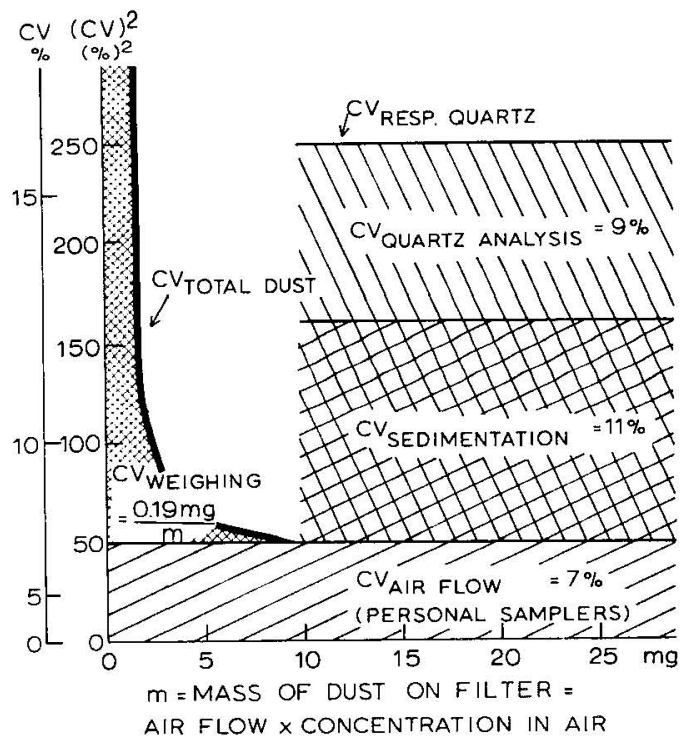

Fig. 1. Coefficients of variation for measuring total dust concentrations and respirable quartz concentrations in air. Contribution of the precisions of air flow measurement, weighing, sedimentation, and quartz analysis.

mass concentration of dust in air follows a general formula. When the random errors are independent of each other, the coefficient of variation of the total dust concentration obeys the equation:

$\mathrm{CV}_{\text {total dust }}=\sqrt{\mathrm{CV}^{2}{ }_{\text {air flow }}+\mathrm{CV}^{2}{ }_{\text {weighing }}}$;

and the mass concentration of respirable quartz, the equation:

$\mathrm{CV}_{\text {resp.quartz }}=\sqrt{\mathrm{CV}_{\text {air flow }}^{2}+\mathrm{CV}_{\text {weighing }}^{2}}+$ $\overline{\mathrm{CV}^{2} \text { sedimentation }}+\mathrm{CV}^{2}{ }_{\text {quartz analysis, }}$

where $\mathrm{CV}_{\text {air flow }}=7 \%$ for personal samplers and $2 \%$ for low-volume samplers,

$\mathrm{CV}_{\text {weighing }}={ }_{\text {weight of dust on a filter }} \frac{0.19 \mathrm{mg}}{0 \%} \cdot 100$, $\mathrm{CV}_{\text {sedimentation }}=11 \%$, and $\mathrm{CV}_{\text {quartz analrsis }}$ $=9 \%$.

The contribution of the different factors is presented in fig. 1. Generally, the sampling times were from 2 to $8 \mathrm{~h}$ and the mass of dust on the filters was heavier than $1 \mathrm{mg}$ in most of the foundry samples. Since the quartz analysis requires, as a minimum amount, $10 \mathrm{mg}$ of sample, the total precision of dust sampling and analysis was better than $20 \%$. 
Temporal variation of dust concentration

Dust spreads at a workplace in a highly irregular manner. It is necessary to know the behavior of the dust concentration in time and space in order to assess the exposure of a worker or a group of workers. In coming to grips with the problem of quantitatively describing the temporal variation of a concentration at a fixed site or job, one can assume that the distribution of dust concentrations is log-normal. The flexibility of the log-normal distribution makes it possible to describe the temporal variation of air pollutant data, which are asymmetrically distributed around the mean value. The use of the distribution in such a case will give more meaningful results than the common assumption of a normal distribution.

In the foundry study, airborne dust samples were collected during two consecutive work shifts. Under the assumption of equal statistical conditions and a negligible autocorrelation between the measurements, the logarithmic standard deviation of 8-h mean concentrations can be calculated for different sites and jobs. The formula is as follows:

$\mathrm{s}=\sqrt{\frac{1}{2 \mathrm{~N}_{\mathrm{i}}=1 \ldots \mathrm{N}} \sum^{\mathrm{N}}\left(\log \mathrm{X}_{1 \mathrm{i}}-\log \mathrm{X}_{2 \mathrm{i}}\right)^{2} .}$

where $\mathrm{X}_{1}=$ concentration during the first sampling, $\mathrm{X}_{2}=$ concentration during the second sampling, and i... N = order of sample pair.
The results of the calculations for iron foundries are presented in table 2. The number of samples from steel and copper alloy foundries was too few for the assessment of their corresponding values, but there seemed to be no difference between the foundry types within the same occupational category.

We found the parameter to be approximately constant with regard to sampling type and job classification. However, in general, the magnitude of the logarithmic standard deviation is affected by the length of the sampling period, the precision of the sampling and analytical methods, and the characteristics of the pollutant emission. In this case, the effect of imprecision in sampling and analysis (less than $20 \%$, as previously stated) is negligible in comparison to the variation of concentration in time. Manual labor or an irregular process with occasional short-term outbursts of contaminant favor a higher value. For instance, the various metal fume concentrations during the melting operation exhibit values from 0.20 to 0.34 (10). Having taken a large series of measurements in foundries, Riediger and Coenen suggested that the dust concentrations can be considered as log-normally distributed with a standard deviation of 0.3 or less, when the sampling time is longer than $1 \mathrm{~h}$ (7).

An attempt was made to determine whether possible, intentionally produced abnormal work conditions would have an effect on dust concentration. It was hypothesized that in these cases activity

Table 2. Logarithmic standard deviation of repeated determinations of total dust concentration at different sites and jobs in 50 iron foundries. The mean concentration (conc.) refers to the arithmetic mean; and the number of sample pairs, to the number of sample pairs used in the calculation.

\begin{tabular}{|c|c|c|c|c|c|c|c|}
\hline \multirow[b]{2}{*}{ Site or job } & \multirow{2}{*}{$\begin{array}{l}\text { Number } \\
\text { of } \\
\text { workers } \\
\text { involved }\end{array}$} & \multicolumn{3}{|c|}{ Breathing zone samples } & \multicolumn{3}{|c|}{ Stationary samples } \\
\hline & & $\begin{array}{c}\text { Mean } \\
\text { conc. } \\
\left(\mathrm{mg} / \mathrm{m}^{3}\right)\end{array}$ & $\begin{array}{c}\text { Loga- } \\
\text { rithmic } \\
\text { standard } \\
\text { deviation }\end{array}$ & $\begin{array}{c}\text { Number } \\
\text { of } \\
\text { sample } \\
\text { pairs }\end{array}$ & $\begin{array}{c}\text { Mean } \\
\text { conc. } \\
\left(\mathrm{mg} / \mathrm{m}^{3}\right)\end{array}$ & $\begin{array}{l}\text { Loga- } \\
\text { rithmic } \\
\text { standard } \\
\text { deviation }\end{array}$ & $\begin{array}{c}\text { Number } \\
\text { of } \\
\text { sample } \\
\text { pairs }\end{array}$ \\
\hline Sand preparation & 110 & 18.3 & 0.18 & 46 & 18.7 & 0.13 & 31 \\
\hline Machine molding & 260 & 6.9 & 0.15 & 48 & 6.5 & 0.14 & 56 \\
\hline Floor molding & 230 & 10.1 & 0.14 & 56 & 8.0 & 0.16 & 68 \\
\hline Coremaking & 230 & 6.7 & 0.19 & 47 & 4.4 & 0.14 & 52 \\
\hline Casting & 150 & 10.0 & 0.24 & 20 & 6.3 & 0.15 & 24 \\
\hline Shake-out & 160 & 13.3 & 0.12 & 28 & 9.1 & 0.13 & 25 \\
\hline Fettling & 420 & 19.8 & 0.21 & 66 & 11.7 & 0.18 & 71 \\
\hline Others & 740 & 7.7 & 0.16 & 26 & 5.2 & 0.17 & 9 \\
\hline
\end{tabular}


would be different during the first day of the 2-day sampling. However, a binomial test performed on the pairwise results (400 iron foundry samples at different jobs) did not indicate such an effect.

\section{Interpretation of air sampling data in terms of exposure dose}

Because exposure dose is defined as the amount of air contaminant inhaled, the sampling method should give the concentration in the inhaled air. It is evident that a personal sampler is more accurate in this respect than an air sampler in a nearby fixed position. The volume of inhaled air should be measured separately or assessed in another manner so that the dose can be expressed in units of mass, e.g., in milligrams. Drasche measured the breathing rates of foundry workers, and the mean rates were from 13.6 to $32.3 \mathrm{I} /$ min during 22 typical foundry jobs (1). Accordingly, an 8-h exposure to a mean concentration of $0.2 \mathrm{mg} / \mathrm{m}^{3}$, the Finnish threshold limit value for $<5 \mu \mathrm{m}$ of quartz, would mean an exposure dose ranging from 1.3 to $3.1 \mathrm{mg}$. The total dust doses of different foundry workers can be estimated with the mean concentrations presented in table 2. The concentrations of respirable quartz have been reported elsewhere (8).

\section{DISCUSSION}

The estimates of the dust exposure during the sampling period are, of course, as accurate and precise as the methods of measurement. But, if one needs to know more, the representativeness of the sampling has to be considered. Exposure evaluations are highly sensitive to error in representativeness, and therefore the foundries, workers, and sampling times of the present study were chosen with care not to cause any biased selection in factors that may influence dust concentration. The objective was to keep the sampling scheme uniform and unaltered from foundry to foundry.

The logarithmic standard deviations presented in table 2 can be used in the generalization or extension of the results of the dust concentration measurements beyond the actual sampling period. With the value of 0.19 , the approximate $90 \%$ confidence interval of a single measurement is attained by dividing the measured untransformed concentration by 2.0 and multiplying it by 2.0. This rule of thumb applies when one estimates the daily variation of a worker's exposure on the basis of one measurement made on him or on the basis of the mean exposure data of his job classification (table 2). For obvious reasons, the estimation refers only to the work conditions which were or, in a statistical sense, might be included in the sampling. The prevalence of different exposure levels in a group of workers can also be approximated with the mean concentration and the logarithmic standard deviation. This statement includes the assumption that the work conditions within a job category are similar on the average in all foundries.

There are two essential variables involved in measuring exposure to any hazard. One is the intensity of the hazard, and the other is the period of exposure to that hazard. In theory many pertinent details about a man's actual job would be required for an accurate measurement of exposure, but in practice his stated occupational category and the length of time he has followed that occupation are the measures by which he is classed into exposure categories (4). An exposure profile for an individual employed in the foundry industry can be constructed from the air sampling data of different jobs and the worker's employment time in these jobs. The precision and accuracy of dust sampling and analysis are excellent in comparison to the errors occurring when air sampling data are used for generalization beyond the sampling period.

\section{ACKNOWLEDGMENTS}

We wish to express our thanks to Ms. Tuula Salmi for her technical assistance with the analytical work.

\section{REFERENCES}

1. DRASCHE, H. Inhalative Schadstoffe und Atemminutvolumen - Bestimmungen bei 
Giessereiarbeitern. Zentralbl. Arbeitsmed. 24 (1974) 169.

2. GERHARDSON, G., ANDERSSON, A., ENGMAN, L., ISAKSSON, G., MAGNUSSON, E. and SUNDQVIST, S. Silikosprojektets slutrapport: Del. 1. Mätmetoder och mätstrategi (Undersökningsrapport AMT 103/74-1). Arbetarskyddsstyrelsen, Stockholm 1976, p. 105.

3. JANSSON, A. Fel vid massbestämning av damm på filter - en pilotstudie (Undersökningsrapport AMTE 101/75). Arbetarskyddsstyrelsen, Stockholm 1975, p. 3.

4. KÄRÄVÄ, R., HERNBERG, S., KOSKELA, R.-S. and LUOMA, K. Prevalence of pneumoconiosis and chronic bronchitis in foundry workers. Scand. j. work environ. \& health 2 (1976): suppl. 1, 64-72.

5. KALLIOKOSKI, P. and PFAFFLI, P. Charcoal sampling method for determining the concentration of styrene in air. Scand. $j$. work environ. \& health 1 (1975) 193-198.

6. OHMAN, H. and ÓDELYCKE, P. Provtagnings- och analysförfaranden för silikosfarligt damm (AI-rapport no. 3). Arbetsmedicinska Institutet, Stockholm 1968. p. 20.

7. RIEDIGER, G. and COENEN, W. Messplanung und statistische Beurteilung. Staub 35 (1975) 445.

8. SILTANEN, E., KOPONEN, M., KOKKO, A., ENGSTRÖM, B. and REPONEN, J. Dust exposure in Finnish foundries. Scand. j. work environ. \& health 2 (1976): suppl. $1,19-31$.

9. SVENSKA GJUTERIFÖRENINGEN. Mätnoggranhet vid dammätning i gjuterier, IVF-resultat, Stockholm 1973, p. 16.

10. TOSSAVAINEN, A. Metal fumes in foundries. Scand. j. work environ. \& health 2 1976): suppl. 1, 42-49. 